\title{
Synthesis of Zinc Oxide nanoparticles using Chrysopogonzizanioidesgrass extract, its applications in Photodegradation and Antimicrobial Activity
}

\section{Paresh More}

Kelkar College: Vinayak Ganesh Vaze College of Arts Science and Commerce

Vrushali Inamdar

Vinayak Ganesh Vaze College of Arts Science and Commerce

\section{Shraddha Suresh}

Vinayak Ganesh Vaze College of Arts Science and Commerce

\section{Shreyas Dindorkar}

Vinayak Ganesh Vaze College of Arts Science and Commerce

\section{Shreya Peddakolmi}

Vinayak Ganesh Vaze College of Arts Science and Commerce

Khushi Jain

Vinayak Ganesh Vaze College of Arts Science and Commerce

Nandini Khona

Kelkar College: Vinayak Ganesh Vaze College of Arts Science and Commerce

\section{Summaiya Khatoon}

Kelkar College: Vinayak Ganesh Vaze College of Arts Science and Commerce

\section{Sunil Patange ( $\nabla$ smpatange@rediffmail.com )}

Shrikrishna Mahavidyalaya https://orcid.org/0000-0003-3970-5537

\section{Research Article}

Keywords: ZnONPs, Photocatalyst, Reactive Brown 2, Antimicrobial activity.

Posted Date: March 30th, 2021

DOl: https://doi.org/10.21203/rs.3.rs-338595/v1

License: (c) (1) This work is licensed under a Creative Commons Attribution 4.0 International License. Read Full License 
Version of Record: A version of this preprint was published at Journal of Materials Science: Materials in Electronics on July 13th, 2021. See the published version at https://doi.org/10.1007/s10854-021-06585Z. 
Synthesis of Zinc Oxide nanoparticles using Chrysopogonzizanioidesgrass extract, its applications in Photodegradation and Antimicrobial Activity

Paresh More $^{\mathrm{a}^{*}}$, VrushaliInamdar ${ }^{\mathrm{a}}$, Shraddha Suresh ${ }^{\mathrm{a}}$, Shreyas Dindorkar ${ }^{\mathrm{a}}$, Shreya Peddakolmi $^{\mathrm{a}}$, Khushi Jain ${ }^{\mathrm{a}}$, NandiniKhona ${ }^{\mathrm{a}}$, SummaiyaKhatoon ${ }^{\mathrm{a}}$ and Sunil Patange $\mathrm{e}^{\mathrm{b}^{*}}$

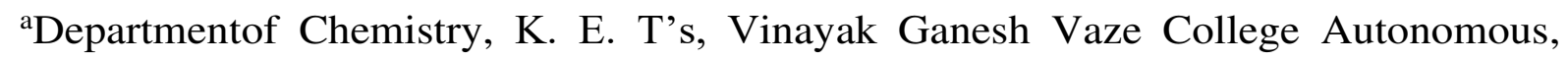
Mulund (E), Mumbai-400081, Maharashtra, India.

${ }^{b}$ Departmentof Physics, ShrikrishnaMahavidyalayaGunjoti, Maharashtra, India.

\begin{abstract}
Zinc oxide nanoparticles (ZnONPs) were synthesized using Zinc nitrate hexahydrate as an oxidizer and Chrysopogonzizanioides (Vetiver) grass as a novel fuel. The X Ray Diffraction pattern as well as the Rietveld refinement showed a single-phase wurtzite structure. The average crystallite size and the lattice strain were estimated using Williamson-Hall plot. A very small value of lattice strain indicates that there is no strain and the crystal lattice is very stable. Thepresence of various functional groups in the plant extract and the Zinc -Oxygen bonding in the ZnONPs were confirmed by FTIR. The surface morphology was investigated using SEM and it showed nanorod like structure. The elemental mapping was carried out using EDAX. The EDAX spectrum suggests formation of $\mathrm{ZnO}$ nanorods along with high proportion of carbon and low proportion of $\mathrm{Si}$ as well as $\mathrm{K}$ might have resulted from the rich organic profile of Chrysopogon zizanioidesgrass extract. Within the UV- Visible Spectrum at $300 \mathrm{~nm}$, the highly blue shifted strong absorption band was observed due to the strong quantum confinement effect. The band gap was observed to be $3.628 \mathrm{eV}$. The photodegradation of RB2 dye was studied over ZnONPs catalyst and it showed excellent photocatalytic activity. The catalyst was active up to five cycles without losing much of its efficiency. Further antimicrobial activity was tested against broad range of micro-organisms namely Staphylococcus aureus, Escherichia coli and much prevalent human fungal pathogen
\end{abstract}


Candida albicans. The Minimum inhibitory concentration (MIC) for each micro-organism was determined using broth micro dilution assay.

Key words: ZnONPs, Photocatalyst, Reactive Brown 2, Antimicrobial activity.

Author for correspondence:smpatange@ rediffmail.com (SMP), paresh.m34@gmail.com(PSM).

\section{Introduction:}

Dye contaminants obtained from textile, printing, production and many other industries have assumed a pivotal role in damaging the environment. In the textile industries during fabric dying, a large quantity of unbind dye is released in the wastewater stream. This wastewater enters the water streams and triggers various environmental problems and health risks. Thus, dying process precipitates highly coloured effluents in water resources, which is aesthetically unpleasant and causes harmful effect on the marine ecosystem [1-2]. Various physical and chemical techniques have been used for the treatments of dyes along with its effluents, however these methods are not practically feasible as they are harmful and some of the methods are highly expensive [3-4]. Numerous methods like osmosis, adsorption, flocculation, etc. have been used for removal of dyes from river, but each method has its own profits and limitations. These limitations can be conquered by using semiconductor photocatalysts like $\mathrm{TiO}_{2}, \mathrm{ZnO}, \mathrm{CdS}, \mathrm{WO}_{3}$ and so on [5-8]. Recently researchers are focussing more on $\mathrm{ZnONPs}$ as compared to other semiconductors as it absorbs wide range of the solar spectrum as well as more light quanta than other semiconductor photocatalyst [9]. Further $\mathrm{ZnO}$ not only has good photocatalytic activity but also has many more other applications which give $\mathrm{ZnO}$ an edge over the most studied $\mathrm{TiO}_{2}$ semiconductor photocatalyst. Additionally, the production cost of $\mathrm{ZnO}$ is also much lower (75\% less) as compared with $\mathrm{TiO}_{2}$ semiconductor photocatalyst. This has excited researchers to synthesize $\mathrm{ZnO}$ nanomaterials and to study its various applications. Researchers had synthesized $\mathrm{ZnO}$ 
nanomaterials by various physical and chemical methods. However green synthesis has more advantages over other methods of preparations. Green methods are eco-friendly as they avoid usage of toxic chemicals, reagents, solvents and they are very convenient to handle. In the green synthesis of nanoparticles, the fruit juices, plant extract, plant latex, etc. acts as fuelling, reducing andcapping agents.ReddyYadav et. al. had used juice of watermelon, sugar cane as a fuel and reported excellent photo catalytic activity of ZnONPs [10-11]. Alamelu et. al. reported synthesis of ZnONPs using tapioca starch in the photodegradation of methylene blue dye [12]. Photo catalytic properties of ZnONps were studied using the plant extract of Cassia fistula and Garcinia xanthochymus [13-14]. Additionally, along with photocatalytic activity, ZnONPs exhibit antimicrobial properties also. In recent years, the development of antimicrobial agents and external coatings has received significant attention. Strong UVadsorption capacity of ZnONPs makes them a very good antibacterial agent. Recent approach of metal nanoparticles has gain importance in the development of potent antimicrobial agents [15]. ZnO material synthesized by spin coating method have shown antimicrobial activity against Gram-positive as well as Gram-negative bacteria; (such as S. pnemoniae, S. aureus, E. coli and E. hermannii) at concentrations ranging from $100-600 \mu \mathrm{g} / \mathrm{ml}$ by agar well diffusion method [16]. The MIC value of ZnONPssynthesized using neem extract was found to be $10.42 \mu \mathrm{g} / \mathrm{ml}$ against Escherichia coli and Salmonella typhi [17]. The antifungal activity of $\mathrm{ZnO}$ biosynthesized using Ziziphus nummularia leaf extract showed effective MIC of 1.25 $\mathrm{mg} / \mathrm{ml}$ for C. albicans and C. glabrate [18]. However, many of the ZnONPsalso suffered from some evident disadvantages, namely weak crystallinity, very restricted spectrum reaction range, less photocatalytic activity, weak antibacterial activity etc. Therefore, an easy and schematic approach to assembling $\mathrm{ZnO}$ nanostructures is extremely desirable for effective solar energy conversion as well as for effective antimicrobial activity. 
In continuation of our earlier research in photodegradation of industrial dyes using ferritte nanoparticles [19-20], Herein, we report green synthesis of ZnONPsusing Chrysopogonzizanioides grass extract. A plant of Indian origin, its oil (extracted from the roots) has been traditionally used as the medicine, an aroma ingredient. However, the aerial part of the plant is discarded and is considered as worthless, we have used this aerial part in the synthesis of $\mathrm{ZnO}$ nanorods. The as-synthesized $\mathrm{ZnONPs}$ were characterized by using various physicochemical techniques such as XRD, FTIR, SEM- EDAX, UV-visible, etc. To the best of our knowledge this is the first study in which the photodegradation of RB2 dye was studied using ZnONPs. The kinetic study and mechanism of RB2 dye degradation over ZnONPswere discussed in detail. Further the antimicrobial activity of ZnONPs against Staphylococcus aureus, (Gram- positive), Escherichia coli (Gram-negative), and Candida albicans (Fungus) were discussed in detailed.

\section{Experimental}

\subsection{Materials}

Zinc nitrate hexahydrate (AR Grade) salt as the zinc precursor was purchased from EMPLURA. Deionized water, distilled water,Chrysopogonzizanioides grass, S. aureusATCC 6538,E.ColiATCC 8739and C. Albicans were collected from Scientific Research Centre,K.E.T's, Vinayak Ganesh Vaze College, Mulund (E), Mumbai-400081, Maharashtra, India. For the dye degradation: Reactive Brown 2 (CAS number: 12236-93-0/70210-17-2) with the Molecular formula: $\mathrm{C}_{31} \mathrm{H}_{20} \mathrm{ClN}_{9} \mathrm{Na}_{4} \mathrm{O}_{12} \mathrm{~S}_{4}$ was collected from Lakhani dye stuff Ambernath Maharashtra, India.

\subsection{Preparation of plant extract.}

Chrysopogonzizanioidesgrass was collected and thoroughly washed with distilled water to eliminate impurities. The grass was dried in the shade for 15 days and the dried leaves were powdered using mortar and pestle. $20 \mathrm{~g}$ of the prepared powder obtained was boiled at $60^{\circ} \mathrm{C}$ in 
300 mLof distilled water. It was heated until the colour of the aqueous solution turned brown. The plant extract was cool at room temperature; filtered using Whatman 41 and the filtrate was used for synthesis of $\mathrm{ZnONPs.}$

\subsection{Synthesis of $\mathrm{ZnONanorods.}$}

$10.0 \mathrm{~cm}^{3}$ of Chrysopogonzizanioidesgrass extract was heated till $60^{\circ} \mathrm{C}$, followed by addition of $2.0 \mathrm{~g}$ of Zinc nitrate hexahydrate. Temperature of the solution was maintained between $60^{\circ} \mathrm{C}$ to $80^{\circ} \mathrm{C}$ under constant stirring till a paste of yellowish white colour was obtained. The paste was sintered at $400^{\circ} \mathrm{C}$ for $2 \mathrm{hrs}$. in the muffle furnace. Yellowish white colour powder obtained was finely pulverized using mortar and pestle. The resulting sample was stored in a glass vial at room temperature. This is the first report in which chemical reagents such as $\mathrm{NaOH}$ or hydrazine or any other chemical stabilizing or capping agents are not used in the synthesis of ZnONPs. As down the line these reagents changes the $\mathrm{pH}$ of water bodies causing threats to aquatic flora and fauna and thus it is of immense ecological concern. Green chemistry principles were followed in the synthesis of ZnONPs by avoiding usage of chemical reagents.

\subsection{Characterisation}

Purity and crystalline structure were characterised at room temperature on Philips (Xpert) Xray diffractometer $(\mathrm{XRD})$ with $\mathrm{Cu} \mathrm{k} \alpha$ radiation having wavelength $1.540 \mathrm{~A}^{0}$. FTIR spectra of the samples were recorded on 3000 Hyperion Microscope with vertex 8 FTIR using $\mathrm{KBr}$ pellets in the range of 400 to $4000 \mathrm{~cm}^{-1}$. The microstructure and the sample morphology of particles were characterized by FESEM ULTRA PLUS manufacture Carl Zeiss Germany. Surface area was analysed using micromeritics BET surface area analyser. Photo degradation of RB2 was studied on UV-Visible spectrophotometer 1800of Shimadzu make. 


\subsection{Photocatalytic degradation of dye}

Degradation ofRB2 dye over ZnONPs was evaluated under solar irradiation. The photoreactor used was $250 \mathrm{~mL}$ borosilicate beaker. $50 \mathrm{~mL}, 20 \mathrm{ppm}$ aqueous solution of RB2 dye containing $0.2 \mathrm{~g}$ of catalyst was stirred in dark for 30 minutes until sunlight irradiation to maintain adsorption equilibria. This was followed by addition of oxidizing agent $\mathrm{H}_{2} \mathrm{O}_{2}$. The mixture was then exposed to irradiation with constant stirring. Aliquots of the irradiating mixture were taken at a constant interval of 30 minutes and were analysed on UV-Visible spectrophotometer (Shimadzu-1800). The reaction was performed by controlling various parameters viz. amount of catalyst, $\mathrm{pH}$ of the dye solution and the amount of $\mathrm{H}_{2} \mathrm{O}_{2}$.

\subsection{Antimicrobial activity}

MIC of ZnO nanorods of S. aureus ATCC 6538, E. coli ATCC 8739 and C. Albicans were performed using the broth micro-dilution assay in 96 well microtiter plates. Briefly, overnight grown bacterial and fungal cultures were re-suspended in Nutrient broth and Sabouraud broth respectively. The OD of all the three cultures was adjusted to 0.1 at $600 \mathrm{~nm}$ to give the count of $8 \times 10^{7}$ cells $/ \mathrm{ml}$. To determine the MIC of each microbial culture, $100 \mu$ of respective broth and $10 \mu \mathrm{l}$ cultures was added into the 96-well plate which gave maximum growth (Positive or Growth Control).Stock solution was prepared by adding ZnONPs in broth and sonicated for 2 minutes to obtain a uniform suspension. A 2-fold dilution was then made to obtain different concentrations of $\mathrm{ZnO}$ nanorods ranging from $1000-0.48 \mu \mathrm{g} / \mathrm{ml} .100 \mu \mathrm{l}$ of varying concentrations $\mathrm{ZnO}$ nanorods solution was added to each well with and without $10 \mu$ lof bacterial or fungal cell suspension to give test and colour blank readings respectively. The micro titre plate was then incubated at $37^{\circ} \mathrm{C}$ for $24 \mathrm{hrs}$ in case of bacteria and at room 
temperature for $48 \mathrm{hrs}$ in case of fungus. The least $\mathrm{ZnONPs}$ concentration in the well where no microbial growth was observed was the MIC. Negative control containing only broth was used in the study. MIC was reported by reading the micro titre plate by micro titre plate reader at $600 \mathrm{~nm}[21-22]$.

\section{Results and Discussion.}

The Rietveld refined XRD pattern of ZnONPs is depicted in the (Fig. 1). The structure was refined with the space group P63m cusingthe Full Prof programme. The XRD analyses designated that $\mathrm{ZnO}$ nanorods have a hexagonal unit cell, single phase wurtzite structure. The crystal data, the observed, calculated anddifference XRD profiles for ZnOnanorods after final cycleof refinement and the refinement factors of $\mathrm{ZnO}$ obtained from $\mathrm{X}$-ray powder diffraction data is depicted in the Table 1 . The observed profile and the calculated profile are perfectly matching with each other (Fig.1). The value ofthe goodness factor $\left(\chi^{2}\right)$ is equal to 2.56, which is attributed as excellent value for the assessment. The profile fitting is excellent if the $\chi^{2}$ value is low, hence the procedure adopted for profile fitting was by minimizing the $\chi^{2}$ function [23].The crystal lattice parameters of $\mathrm{ZnO}$ nanorods are in the good agreement with the literature report (JCPDS No. \#36-1451). Williamson-Hall plot for ZnONPsis illustrated in the inset of Fig. 1. The values of average crystallite size and the lattice strain are $42 \mathrm{~nm}$ and 0.0027 respectively, obtained from a linear least square fitting to $\eta \cos \theta-\sin \theta$. The lattice strain value is low, indicating stable structure of ZnONPs, this may be due to the green method of synthesis. The crystal structure of ZnONPs from the Rietveld refinement is depicted in the Fig. 2.

The SEM images and EDS spectra of as-synthesized ZnONPsis revealed in the Fig.3. The SEM images manifest nanorod-like structures. The low magnification images (Fig. 3a and 3b) show that these nanorod-like nanostructures are grown by gathering of small distorted hexagonal shape like structures. The diameter of nanorod-like structures is in between 20-40 
$\mathrm{nm}$. The high magnification image (Fig. 3c) depicts that; the sample consists of agglomerated nanostructures. The corresponding EDS spectra is depicted in Fig.3d, it demonstrates the atomic percentage of $\mathrm{Zn}$ and $\mathrm{O}$ in nanorod-like structure and are observed to be 45.3 and 38.92. Further atomic percentage of $\mathrm{C}, \mathrm{Si}$ and $\mathrm{K}$ were found to be $15.07,0.33$ and 0.37 respectively. High proportion of carbon along with low proportion of $\mathrm{Si}$ and $\mathrm{K}$ might have resulted from the rich organic profile of Chrysopogonzizanioidesgrass extract.

The FTIR spectrum of Chrysopogonzizanioidesgrass extract and the biosynthesized ZnONPs is shown in Fig.4. The FTIR spectrum of Chrysopogonzizanioidesgrass extract (Fig. 4a) exhibited several peaks at 3400, 2900, 2800, 1600, 1400, 1125, 900, 800,650, $490 \mathrm{~cm}^{-1}$. The peaks at $3400(\mathrm{O}-\mathrm{H}), 1600(\mathrm{~N}-\mathrm{H})$, and $1125(\mathrm{C}-\mathrm{O})$ or $900(\mathrm{RCOO}) \mathrm{cm}^{-1}$ are related to alkaloids, flavonoids, and phenolic compounds, respectively [24-27], whereas the broad stretching band at $3400 \mathrm{~cm}^{-1}$ stipulates the existence of hydrogen-bonded groups. These results signify the presence of flavonoid derivatives in the plant extract. There is shift in the position as well as the intensity of the band of the spectrum of ZnONPs (Fig. 4b). This is due to the interrelation of the functional groups of the flavonoids as well as phenols with the ZnONPs. The prominent and very sharp band was observed at $488 \mathrm{~cm}^{-1}$ because of the stretching vibration of $\mathrm{Zn}-\mathrm{O}$ bond in tetrahedral coordination. A very weak band at $654 \mathrm{~cm}^{-1}$ was allocated to the stretching vibrations of $\mathrm{Zn}-\mathrm{O}$ bonds in octahedral coordination. Tetrahedral co-ordinations are very strong as compared to the octahedral co-ordinations in the synthesized samples this further confirms wurtzite structure of ZnONPs [24-25].The band at $1382 \mathrm{~cm}^{-1}$ is assigned to the asymmetric stretching vibrations of $\mathrm{C}=\mathrm{O}$ group due to Lewis acidity. Whereas band at $1629 \mathrm{~cm}^{-1}$ is attributed to the symmetric stretching vibrations of $\mathrm{C}=\mathrm{O}$ group because ofBronsted acidity. The band at $2856 \mathrm{~cm}^{-1}$ and $2918 \mathrm{~cm}^{-1}$ are because of $\mathrm{C}-\mathrm{H}$ bending and C$\mathrm{H}$ stretching vibration respectively. The broad hump at $3431 \mathrm{~cm}^{-1}$ isascribed to- $\mathrm{OH}$ stretching vibration due to $\mathrm{H}_{2} \mathrm{O}$ which indicates that at the surface of nanoparticles water molecule is 
adsorbed. The ZnONPs gets easily dispersed into the water (RB2 dye solution prepared in water) because of surface hydroxyl groups [26].

The optical properties of as prepared Chrysopogonzizanioidesgrass extract and ZnONPs were examined using UV- Visible spectrophotometer in the range of $200 \mathrm{~nm}$ to $800 \mathrm{~nm}$. The light brown coloured extract showed a small hump in the near UV region (297.2 $\mathrm{nm})$ as shown in the Fig. 5a. The observed hump was probably due to the plant biomolecules (polyphenols, flavonoids, etc.), which have crucial role in the reduction of metal ions [27-28].To study optical properties of ZnONPs, the particles were dispersed in deionised water followed by ultrasonicationforabout15 minutes. The resultant solution showed a very strong band at 300 nm Fig.5a, this band is very much blue shifted when they are compared with their bulk counterpart (360 nm). The strong blue shifted absorption edge confirms that ZnONPs showed a very strong quantum confinement effect [29]. The change in the spectrum provided the first conformation for the formation of ZnONPs. The optical band gap was calculated using UVVisible spectra by Tauc plot method (Fig. 5b). Extrapolating of straight line in the plot of $(\alpha h v)^{2}$ vs Energy $(h v)$ gives the value of optical band gap of ZnO NPs[30]. The optical band gap was found to be $3.628 \mathrm{eV}$ which shows slight increase $(\sim 0.4 \mathrm{eV})$ than the ideal value (at room temperature). The increase in the band gap also supports that ZnONPs exhibits quantum confinement effect. The photocatalytic activity was carried out using ZnONPs as a catalyst to study the photodegradation of RB2 dye at various reaction conditions. The UV-Visible spectrum showed absorption band at $463 \mathrm{~nm}$ and a small hump at $280 \mathrm{~nm}$ assigned to the visible and UV region respectively.

Surface area of ZnONPswas estimated using (BET) surface analyzer at the temperature of$196{ }^{\circ} \mathrm{C}$. The samples were prepared with the flow of $\mathrm{N}_{2}$ gas at the temperature of $150{ }^{\circ} \mathrm{C}$ for 2 hours. The Langumir theory was extended by Brunauer, Emmett and Teller and they gave following equation[31]. 
$\frac{1}{\mathrm{Q}\left[\left(\frac{\mathrm{P}_{0}}{\mathrm{P}}\right)-1\right]}=\frac{\mathrm{C}-1}{\mathrm{Q}_{\mathrm{m}} \mathrm{C}}\left(\frac{\mathrm{P}}{\mathrm{P}_{0}}\right)+\frac{1}{\mathrm{Q}_{\mathrm{m}} \mathrm{C}}(1)$

The terms involved in the equations are, $\mathrm{P}$-equilibrium pressure, $\mathrm{P}_{0}$-saturation pressure, $\mathrm{Q}$ amount of gas adsorbed on the adsorbate, $\mathrm{Q}_{\mathrm{m}}$-monolayer adsorbed and $\mathrm{C}$ is the BET constant. The BET plot $\left(1 /\left[\mathrm{Q}\left(\mathrm{P}_{0} / \mathrm{P}\right)\right]\right.$ vs $\left.\mathrm{P} / \mathrm{P}_{0}\right)$ of the ZnONPs is depicted in the Fig. 6a. It is clear from the figure that the plot is linear, and the values obtained from the slope (A) and intercept (I) gave unique values of $\mathrm{Q}_{\mathrm{m}}$ and $\mathrm{C}$ respectively. From the BET plots different variables were calculated such as slope $-3.708996 \mathrm{~g} / \mathrm{cm}^{3}$, Intercept $-0.110422 \mathrm{~g} / \mathrm{cm}^{3}, \mathrm{Qm}_{\mathrm{m}}-0.2618 \mathrm{~cm}^{3} / \mathrm{g}, \mathrm{C}-$ 34.589221, Stotaland $\mathrm{S}_{\text {BET }}-1.1398 \mathrm{~m}^{2} / \mathrm{g}$ and pore width $77.3224 \AA$. The various empirical and computational values required for plotting the curve are tabled in Table 2.The values of ${ }^{\prime} \mathrm{Qm}$ ' and ' $\mathrm{C}$ ', total surface area $\left(\mathrm{S}_{\mathrm{total}}\right)$ and specific surface area $\left(\mathrm{S}_{\mathrm{BET}}\right)$ were calculated according to equation (2), (3), (4) and (5).

$$
\begin{aligned}
& \mathrm{Q}_{\mathrm{m}}=\frac{1}{(\mathrm{~A}+\mathrm{I})}(2) \\
& C=1+\frac{A}{I}(3) \\
& S_{\text {total }}=\frac{Q_{m} N_{S}}{V}(4) \\
& S_{B E T}=\frac{S_{\text {total }}}{M}(5)
\end{aligned}
$$

Where Avogadro's number is ' $N$ ', The molecular cross-sectional area is ' $\mathrm{s}$ ' $\left(0.1620 \mathrm{~nm}^{2}\right)$, the molar volume of the adsorbate gas is ' $\mathrm{V}$ ' and mass of adsorbent sample is ' $\mathrm{M}$ ' $(0.1304 \mathrm{~g})$. The Stotaland $\mathrm{S}_{\text {BET }}$ were found to be $1.5839 \mathrm{~m}^{2} / \mathrm{g}$ and $1.138 \mathrm{~m}^{2} / \mathrm{g}$ respectively. Thet-plot and BJH adsorption methods were utilized to calculate pore volume and pore size and were found to be $0.00203 \mathrm{~cm}^{3} \mathrm{~g}^{-1}$ and $77.3224 \mathrm{~nm}$ respectively. The value of BET surface area of $\mathrm{ZnO}$ nanorods was $1.5839 \mathrm{~m}^{2} / \mathrm{g}$. The nitrogen adsorption and desorption isotherms of $\mathrm{ZnO}$ nanorods was recorded and depicted in the Fig. 6b. According to the IUPAC classification, the recorded isotherms are of the type IV [32]. The adsorption-desorption isotherm of 
ZnONPsforms type IV hysteresis loop indicating self-assembly of small nanoparticles which exist as complex porous structure.Also, it is to be noted that the type IV isotherms are typical isotherm for mesoporous materials [33]. Mesoporous materials are good adsorbent and hence RB2 dye was well adsorbed at the surface of ZnONPs which leads in the rapid photo degradation of RB2 dye.

The degradation of RB2 dye was monitored through the variation observed in the intensity of the absorption peak of the RB2. During beginning $(\mathrm{t}=0)$, the absorption band was observed at $463 \mathrm{~nm}$ in visible region and a small hump at $280 \mathrm{~nm}$ in the UV region. To demonstrate the activity of ZnONPs catalyst on RB2 solution, the experiment was carried out in solar irradiation. To the $50 \mathrm{~mL}$ of $20 \mathrm{ppm} \mathrm{RB} 2$ solution, $25 \mathrm{mg}$ of the catalyst was mixed, and the solution was kept on the magnetic stirrer for adsorption and desorption in the dark for 30 minutes. Followed by addition of $0.2 \mathrm{~mL} \mathrm{H}_{2} \mathrm{O}_{2}$ and at a maintained $\mathrm{pH}$ of the solution 2.5, the beaker was kept in the sunlight to record the absorbance of the dye solution at the interval of 30 minutes using UV-Visible spectrophotometer. The absorption peak intensity of the RB2 at $463 \mathrm{~nm}$ gradually decreased in intensity and there is new band observed with the increase in the irradiation time as shown in the Fig. 7a. These observations confirmed the degradation of chromophore responsible for the colour of RB2 dye. Further the hump due to aromatic rings vanished which indicate degradation of aromatic rings. The results indicate that during 30 minutes of adsorption desorption in the dark, the dye degradation was $2.32 \%$, after $30,60,90$ and 120 minutes the degradation was $77.27 \%, 87.27 \%, 91.81 \%$ and $99.98 \%$. The as synthesized catalyst ZnONPs is very effective in the photo degradation of RB2 with almost $100 \%$ degradation in just 120 minutes. The coefficient of determination $\left(\mathrm{R}^{2}\right)$ was found to be 0.998 which is very close to unity. Thus, the reaction follows pseudo first order kinetics [34] Different control experiments were carried out in the presence of ZnONPs using UV-Visible spectroscopy and the data is depicted in the Fig.7b. It is clear from the graph that a very 
negligible dye was degraded in the absence of catalyst and $\mathrm{H}_{2} \mathrm{O}_{2}[\mathrm{RB} 2+$ light (a)]. Dye degradation efficiency was improved very slightly in the presence ([RB2 $+\mathrm{H}_{2} \mathrm{O}_{2}+$ light (b)], and absence $\left[\mathrm{RB} 2+\mathrm{H}_{2} \mathrm{O}_{2}+\operatorname{dark}(\mathrm{c})\right]$ of light. The dye degradation efficiency was increased when the catalyst was added $[\mathrm{RB} 2+\mathrm{ZnO} \mathrm{NPs}+$ dark (d)]. In the sunlight the dye degradation efficiency increases to the great extent $[\mathrm{RB} 2+\mathrm{ZnO} \mathrm{NPs}+$ light (e)]. This is since photo-induced process produces electron-hole pairs, which when migrate throughout the Zinc oxide crystal and eventually responsible for increasing degradation efficiency [35]. However, the rate of the reaction was drastically increased to $100 \%$ when the reaction was carried out with $\left[\mathrm{RB} 2+\mathrm{ZnO} \mathrm{NPs}+\right.$ light $+\mathrm{H}_{2} \mathrm{O}_{2}$ (f)], also the rate constant was found to be highest in this case as depicted in the Fig.7b.

$\mathrm{ZnO}$ is an excellent semiconductor oxide which shows the semi-conductive nature at room temperature. Broad direct band gap width of $3.37 \mathrm{eV}$, high excitation binding energy (60 $\mathrm{meV}$ ) allows $\mathrm{ZnO}$ to show good photocatalytic activity along with anti-microbial and antifungal properties. When $\mathrm{ZnO}$ is irradiated with solar radiation, the photonic energy (hv) which is equal to or greater than threshold energy $\left(E_{g}\right)$, promotes the electrons from filled valence band to an empty conduction band. This photo-induced process produces electronhole pairs which has ability to delocalize throughout the $\mathrm{ZnO}$ lattice. The holes thus produced reacts with water molecules resulting in the formation of $\mathrm{H}^{+}$ion and $\mathrm{OH} \bullet$ radical. The electron reacts with oxygen molecules to form superoxide ions, which in turn reacts with $\mathrm{H}^{+}$formed in the reaction (II) to formhydroperoxyl radicals $\left(\mathrm{HO}_{2} \bullet\right)$.Two hydroperoxyl radicals combine to give hydrogen peroxide which in turn reacts with superoxide ions yielding hydroxyl free radicals having very high oxidizing ability. The attack of resulting hydroxyl radicals on adsorbed RB2 molecules results in rapid formation of intermediate compounds which gets converted to $\mathrm{CO}_{2}$ and $\mathrm{H}_{2} \mathrm{O}$. The conversion of $\mathrm{RB} 2$ dye into less harmful degradation products is due to the formation of active oxygen species. Based on the above results, we 
proposed the photocatalytic mechanism using ZnONPs under sunlight irradiation.Possible Mechanism for the catalytic RB2 dye degradation under sunlight irridation using ZnONPsis depicted in theFig. 8 .

$$
\begin{aligned}
& \mathrm{ZnO} \mathrm{NPs} \stackrel{\mathrm{Eg}_{g}}{\rightarrow} \mathrm{e}^{-}+\text {holes } \\
& \text { holes }+\mathrm{H}_{2} \mathrm{O} \rightarrow \mathrm{H}^{+}+\mathrm{OH}^{\bullet} \\
& \mathrm{e}^{-}+\mathrm{O}_{2} \rightarrow \mathrm{O}_{2^{\bullet}}^{\bullet^{-}} \\
& \mathrm{O}_{2^{\bullet-}}+\mathrm{H}^{+} \rightarrow \mathrm{HO}_{2} \bullet
\end{aligned}
$$

$2 \mathrm{HO}_{2} \bullet \rightarrow \mathrm{H}_{2} \mathrm{O}_{2}+\mathrm{O}_{2} \uparrow \stackrel{\mathrm{O}_{2} \bullet^{-}}{\rightarrow} \mathrm{OH} \bullet+\mathrm{OH}^{-}+\mathrm{O}_{2}$

$$
\mathrm{RB} 2+\mathrm{OH} \bullet \rightarrow \text { Intermediates } \rightarrow \text { Degradation Products }\left(\mathrm{CO}_{2}+\mathrm{H}_{2} \mathrm{O}\right)
$$

Catalyst loading plays a very crucial role in photodegradation process. It is one of the most importantparameters in the catalysis process. To make the process economically viable and industrially important, optimum amount of the catalyst is to be used in the experiment. The effect of catalyst on the degradation of RB2 at dye concentration of $20 \mathrm{mg} / \mathrm{L}, \mathrm{H}_{2} \mathrm{O}_{2}-0.2 \mathrm{~mL}$ and $\mathrm{pH}-2.5$ is depicted in the Fig.9a. The results indicate that the rate of dye degradation decreases as the concentration of the catalyst increases. Due to increase in concentration of the catalyst the turbidity of the solution increases and there will be hindrance to the sunlight in the penetration of the light through the dye solution. This leads to decrease in the rate of photo-phenton process and the degradation efficiency decreases [36]. Based onobservations, the optimized weight of the catalyst is $0.025 \mathrm{~g} / \mathrm{L}$. The rate constant was also highest with this concentration as depicted in the Table 3. All the experiments were performed with $0.025 \mathrm{~g} / \mathrm{L}$ of photocatalyst. 
$\mathrm{pH}$ of the solution plays a very critical role in the photo- degradation of RB2 dye. To make the photo degradation process very effective and economical, the process is to be carried out at appropriate $\mathrm{pH}$. Hence experiments were carried out to check optimum amount of $\mathrm{pH}$ to be maintained to carry out the reaction. The role of $\mathrm{pH}$ in the photodegradation of $\mathrm{RB} 2$ at constant dye concentration of $20 \mathrm{mg} / \mathrm{L}$, catalyst $0.025 \mathrm{~g} / \mathrm{L}$ and $\mathrm{H}_{2} \mathrm{O}_{2} 0.2 \mathrm{~mL}$, is depicted in the Fig.9b.The results indicated high photo degradation at lower $\mathrm{pH}$ with maximum photo degradation with $\mathrm{pH} 2.5$. Hence all the experiments were carried out at $\mathrm{pH} 2.5$. The rate constant was also highest with this $\mathrm{pH}$ as depicted in the Table 3.

To make the process cost effective control dosages of $\mathrm{H}_{2} \mathrm{O}_{2}$ is essential as it is costly chemical. The effect of $\mathrm{H}_{2} \mathrm{O}_{2}$ dosage on the degradation of $\mathrm{RB} 2$ at constant dye concentration of $20 \mathrm{mg} / \mathrm{L}$, catalyst $0.025 \mathrm{~g} / \mathrm{L}$ and $\mathrm{pH}-2.5$ is depicted in the Fig.9c.The results indicate that the rate of the photo degradation and the rate constant increases as the concentration of $\mathrm{H}_{2} \mathrm{O}_{2}$ increases. Based on above observations, the optimized concentration of $\mathrm{H}_{2} \mathrm{O}_{2}$ is $0.2 \mathrm{~mL}$. The rate constant was also highest with $0.2 \mathrm{~mL}$ of $\mathrm{H}_{2} \mathrm{O}_{2}$ as depicted in the Table 3 .

It is clear from the photodegradation mechanism that $\mathrm{H}_{2} \mathrm{O}_{2}$ is generated during the degradation process (equation $\mathrm{V}$ of mechanism) hence only $0.2 \mathrm{~mL}$ of $\mathrm{H}_{2} \mathrm{O}_{2}$ is required for optimising the process. The superoxide ions generated (equation III of mechanism) combine with $\mathrm{H}_{2} \mathrm{O}_{2}$ to generate hydroxyl radical $(\mathrm{OH} \bullet)$ which breaks organic pollutant to produce intermediate and the intermediate gives the final product $\mathrm{CO}_{2}+\mathrm{H}_{2} \mathrm{O}$ [37]. The stability and reusability of the ZnONPs photocatalystwere tested over RB2 dye, after recycling to replicate the experiments under identical conditions Fig. 9d. More specifically, under sunlight irradiation, ZnONPs photocatalystdisplayed sustained and consistent behaviour up to the 5th cycle which proves the catalyst's stability and recyclability.

\section{Antimicrobial Activity.}


Due to the wide exploitation of antibiotics in modern era the rise of antibiotic resistant bacteria has been increasing exponentially. To put this situation under control, it is necessary to find antibiotics which show broad spectrum killing. Nanoparticles have broad range of applications in many fields of life sciences. ZnONPs has known to show promising killing effect against planktonic cultures and has proven to effectively inhibit biofilm formation by gram positive or negative microbes. The teichoic acid filaments present in peptidoglycan layer of gram-positive bacteria are negatively charged. Also, the cell wall of gram-positive bacteria has abundant pores. Positively charged ZnONPs and their nanosized makes them ideal candidate to penetrate easily, produce cellular lesions and induce cell death in gram positive bacteria[38].The cell wall composition of gram-negative is complicated, wherein the peptidoglycan is held together with lipopolysaccharide, lipoproteins and phospholipids which effectivelyform a barrier that restricts penetration of nutrients and removal of catabolism products at the level of porins [38].

We have observed microbial static effect of ZnONPs on a broad range of microbes. The study was done in triplicates, it was seen that $\mathrm{ZnO}$ showed broad spectrum inhibition of microbial cultures.For the analysis of antimicrobial action of the ZnONPs, a gram positive bacteria $S$. aureus ATCC 6538, a gram negative bacteria E.coli ATCC 8739 and a fungal strain C. albicans were selected as model organisms. It was seen that, with the varying concentration of ZnONPs nanoparticles the percentage inhibition of microbes also varied. More the concentration of ZnONPs more the percentage inhibition of microbes, thus concentration of ZnONPs was directly proportional to the percentage inhibition of microbes.A graph of concentration of ZnONPs versus percentage inhibition of microbes $(S$. aureus, E. coli and C. albicans) was plotted (Fig.10). Percentage inhibition for each was calculated by the ratio of absorbance of test solution to the absorbance of control solution multiplied by 100 . 
Percentage Inhibition of Microbes $=\frac{\text { Absorbance of test solution }}{\text { Absorbance of control solution }} \times 100$

In the graph, it is seen that $\mathrm{ZnO}$ NPs shows a $100 \%$ inhibitory concentration (IC 100) of 1.0 $\mathrm{mg} / \mathrm{ml}$ and $0.5 \mathrm{mg} / \mathrm{ml}$ forE. coli and C. albicans respectively. However, for S. aureusZnO NPs shows $70 \%$ inhibitory concentration (IC 70)of $0.5 \mathrm{mg} / \mathrm{ml}$. After the above concentrations of $\mathrm{ZnO}$ NPS the percentage inhibition of microbes decreases with the decreasing concentration of $\mathrm{ZnO}$ for all the three model microorganisms (Fig.10).

ZnONPswere found to be effective againstGram positive and Gram-negative bacteria as well as against fungal strain, which indicates it can act as broad spectrum microstatic drug. $E$. coli ATCC 8739 was treated with ZnONPs, showed growthinhibition and leading to death in the E.coli cells at very low concentration. The MIC value of ZnONPs against E.coli found (1.0 mg/mLIC100) (Fig.11a) which is very low than the formerly reported values for bare $\mathrm{ZnO}$ [39-41], doped $\mathrm{ZnO}$ [42] and $\mathrm{ZnO}$ materials in combination with antibiotics . In case of E. coli ATCC8739, ZnO-NP hasa higher efficiency in opposition to the strain in planktonic growth. Active pathogenic growth of S. aureus ATCC 6538 was treated by $\mathrm{ZnO}-\mathrm{NP}$, and it was found that cell growth was inhibited in the presence of very low concentration. The growth inhibition and death in microbes observed in the ZnONPs treated wells and the MIC (0.5 mg/mL IC 70) (Fig.11b)obtained against S. aureus ATCC 6538 is very low than the previously reported values[43-44]. The ZnONPs compounds were tested for antifungal activity toward one reference pathogenic fungal strain, $C$. albicans.ZnONPs shows the most promising antifungal activity, being active against the fungal strain in planktonic growth state (0.5 mg mL-1 IC 100) (Fig.11c). ZnO obstructs membrane integrity by producing reactive oxygen species that destroy fungi [45-49]. Furthermore, production of hydrogen peroxide and $\mathrm{Zn}^{2+}$ has played a key role in the antifungal activity of nanoparticles. The obtained MICs are 
lower than previously reported several zinc oxide-based materials $\mathrm{ZnO}$ [39, 41], Pd-doped ZnOand $\mathrm{ZnO}$-chitosan composites [46], polycarbonate-based cationic polymer and different antibiotics[41, 50]. Based on the above resultsthe plausible mechanism for Antimicrobial activityofZnONPsis depicted in theFig. 12.

\section{Conclusion:}

This study signifies a simple green synthetic approach towards the synthesis of ZnONPs using aqueous Chrysopogonzizanioidesgrassextract. The photocatalytic degradation by $\mathrm{ZnO}$ NPs was checked on RB2 dye under solar irradiation. The catalyst is very stable and showed excellent catalyticefficiency up to five cycles. Further it describes the use of ZnONPs as antibacterial and antifungal agent. The antibacterial and antifungal results were very promising.

\section{Acknowledgement:}

Authors are thankful to TIFR Faculties, Dr. Deepa Khushlani and Mr. BalsahebChandanshive for BET Analysis, Mr. Nilesh Kulkari for XRD, Mrs. Bhagyashri Chalke for SEM,EDAX, SAIF IIT Bombay for FTIR,Dr.Kiran Kharat from Department of Zoology K.E.T's, V.G.Vaze College Autonomous for discussion on Antimicrobial activity and Principal Dr.B.B.Sharma for providing all the infrastructure facilities. 


\section{References:}

[1] N.Barka, A. Assabbane, A. Nounach, L. Laanab, Y.A. Ichou, Desalination, 235, 264(2009).

[2] G. Zhu, H.Mirabbos, K. Kenichi, Xu Cai, M. Nobuhiro, K. Okada, P. Liu, J. Zhou, Materials Chemistry and Physics, 142,95(2013).

[3] N.Mahmoodi, Water Air Soil Poll., 224, 1419(2013).

[4] N. Mahmoodi, F. Najafi, Mesopor. Mater., 156, 153(2002).

[5] B. Liu, T. Torimoto, H. Yoneyama, J. Photochem.Photobiol. A: Chem., 113,93(1998).

[6] I. Konstantinou, T. Sakellarides, V. Sakkas, T. Albanis, Environ. Sci. Technol., 35,398(2001).

[7] Y. Kwon, K. Song,W.Lee, G.Choi, Y.RagDo., J.Catal., 191, 192(2000).

[8] H. Lin, S. Liao, S. Hung, J. Photochem. Photobiol. A: Chem., 174,82(2005).

[9] S. Sakthivel, B. Neppolian, M. Shankar, B. Arabindoo, M. Palanichamy, V. Murugesan, Energy Mater. Sol. C., 77,65(2003).

[10] L.ReddyYadav, D. Kumar, K.Kavithra, H. Rajanaika, B. DarukaPrasad, H.Nagabhushana, G. Nagaraju, International Journal of Nanoscience., 15,1650006(2016).

[11] L.ReddyYadav, B. Archana, K. Lingaraju, K. Kavitha, D.Suresh, H. Nagabhushana, G.Nagaraju, International Journal of Nanoscience 15(2),1650013(2016).

[12] K.Alamelu, H. RajaNaika, H. Nagabhushana, T. Ramakrishnappa, R. Geetha, Balkrishna, G. Nagaraju, Materials Characterization., 99, 266(2015).

[13] D.Suresh, P.Nethravathi, Udaybhanu, H.Rajanaika, H. Nagabhushana, S. Sharma, Materials Science in Semiconductor processing., 31,446(2015).

[14] P.Nethravathi, G.Sgruthi, D. Suresh, Udaybhanu, H. Nagabhushana, S. Sharma, Ceramic International., 41, 8680(2015).

[15] R.Singh, W.James, Jr.Lillard, Experimental and molecular pathology., 86(3),215(2009).

[16] K. Kaviyarasu, C. Magdalane, K. Kanimozhi, J. Kennedy,B. Siddhardha,E. Reddy, N. Rotte, C.Sharma,F. Thema, D. Letsholathebe, G. Mola, Journal of Photochemistry and Photobiology B: Biology., 173,466(2017).

[17] B.Thakur, A.Kumar, D.Kumar, South African Journal of Botany., 124, 223(2019).

[18] H. Padalia, S.Chanda, Artificial cells, nanomedicine, and biotechnology., 45(8), 1751(2017).

[19] K. Jangam, K. Patil, S. Balgude, S. Patange, P. More, Journal of Physics and Chemistry of Solids., 148,109700(2021).

[20]K. Jangam, K. Patil, S. Balgude, S. Patange, P. More, RSC Adv., 10, 42766(2020). 
[21] M.Alekish, Z. Ismail, B. Albiss, S. Nawasrah, Veterinary World., 11(10), 1428 (2018).

[22] P.Mariappan, K.Krishnamoorthy, J. Kadarkaraithangam, M. Govindasamy, Nanomedicine :Nanotechnology, Biology, and Medicine., ,7,184(2011).

[23] L. McCusker, R.VonDreele, D.Cox, D. Louër, P. Scardi, J ApplCryst., 32,36(1999).

[24] S. Kumar, S. Mukherjee,K. Singh, S. Chatterjee, A.Ghosh, J. Appl. Phys., 110,103508(2010).

[25] Y. Guo, X. Cao, X.Lan, C. Zhao, X. Xue,Y. Song, J. Phys. Chem. C.,112, 8832(2008).

[26] S. Darshan, J. Ranjana, Ceramics International., 43, 8488(2017).

[27]A. Mittal, C. Yusuf, U. Banerjee, Biotechnology Advances., 31, 346(2013).

[28] A. Imran, C.Peng, Y. Tong, N.Iffat., RSC Advances., 8, 8878(2018).

[29]A.Moharram, S.Mansour, M.Hussein, M.Rashad, Journal of Nanomaterials,2014,716210 (2014).

[30] M.Debanath, S.Karmakar, Materials Letters., 111, 116 (2013).

[31] D. He, Z. Huan, M. Wang, J Mater Sci: Mater Electron., 30, 1468(2019).

[32] K.Sing, D.Everett, R. Haul, Pure and Applied Chemistry., 57(4), 603 (1985).

[33] A.Alswatta, M. Ahmad, N.Al-HadaH. Kamari,M. Hussain, N. Ibrahim, Results in Physics., 7 , 723 (2017).

[34] N.Laouedj, A. Elaziouti, A. Bekka, Fibers and Polymers., 13(3), 303 (2012).

[35] W. Zhansheng,X. Chen, X. Liu, X. Yang, Y. Yang, Nanoscale Research Letters., 147,1(2019).

[36] T. Soltani, M.H. Entezari, Ultrason.Sonochem., 20, 1245(2013).

[37] Y.Zoang, Z. Li, X.Wang, J. Ma, Y.Men, Ceram.Int., 40(7), 10375 (2014).

[38] J.John, Thwaites, H. Neil, Mendelson, Advances in Microbial Physiology.,32, 173(1991).

[39] M.Premanathan, K.Karthikeyan, K. Jeyasubramanian, G.Manivannan, Nano med, 7, 184(2011).

[40] D.Ong, P. Wu, P. Su, D. Wang, H. Tian, Mater. Lett., 70, 94(2012).

[41] R.Bhande, C.Khobragade, R.Mane, S. Bhande, J. Nanopart. Res., 15, 1413 (2013).

[42] B.Guo, P.Han, L. Guo, Y.Cao, A. Li, J.Kong, H.Zhai,D.Wu, Nanoscale Res. Lett., 10, 1 (2015).

[43] J. Yunhong, Z.Lingling, W.Dongsheng, D.Yulong, Materials Science and Engineering C., 69, 361(2016).

[44] N. Sharma, J.Kumar, S.Thakur, S. Sharma, V. Shrivastava, Today., 5(1),50 (2013). 
[45] H.Chen,C. Liu, D. Chen, K.Madrid, S.Peng, X. Dong, M.Zhang, Y. Gu.; Mol. Pharm, 12, 2505 (2015).

[46] B.Guo P. Han, Li. Guo, Y. Cao, A. Li, J. Kong, H. Zhai, D. Wu, Nanoscale Research Letters 10, 336 (2015).

[47] Y. Wang, Q. Zhang, C. Zhang, P. Li, Food Chemistry., 132, 419 (2012).

[48] D.Monteiro, A.Takamiya, L. Feresin, L. Gorup, E.deCamargo, A.Delbem, Med Mycol., 52(6), 627 (2014).

[49] M. Kratk, J.Vinsov, V.Buchta, ScientificWorld Journal., 2012, 290628(2012).

[50] A. Huh, Y. Kwon, J Control Release., 156, 128 (2011).

\section{Figure Caption:}

Figure 1: Rietveld refinement of XRD pattern and Inset:Williamson-Hall plot for $\mathrm{ZnONPs.}$

Figure 2: Hexagonal Closed Packed Wurtzite crystal structure of ZnONPs with space group P $63 \mathrm{~m} \mathrm{c}$.

Figure 3: SEM images and EDS spectra of as-synthesized $\mathrm{ZnO}$ nanostructures at different magnifications.

Figure 4: a) FTIR spectra of Chrysopogonzizanioidesgrass extract and b) ZnONPsin the range of $400-4000 \mathrm{~cm}^{-1}$.

Figure 5: a) UV-Visible absorption spectrum of Chrysopogonzizanioidesgrassextractand ZnONPs b) Optical band gap of synthesized ZnONPs.

Figure 6: a) The fitting curve of the BET surface area and b) Nitrogen adsorptionisotherm of $\mathrm{ZnONPs.}$

Figure 7: a) Spectral Change during the degradation of RB2 dye in the presence of ZnONPs. b) A Plot of the change absorbance Vs Irradiation time in the presence of ZnONPs Catalyst.

Figure 8: Possible Mechanism for the photocatalytic RB2 dye degradation under sunlight irridation using ZnONPs.

Figure 9. Effects of a) Catalyst b) $\mathrm{pH}$ variation c) $\mathrm{H}_{2} \mathrm{O}_{2}$ Variation d) Recyclability of ZnONPs.

Figure 10: Percentage inhibition of microbes by different concentration of $\mathrm{ZnO}$ on $S$. Aureus, E. Coli and C.albicans.

Figure 11: Minimum inhibitory concentration (MIC) for a) E. coli b) S. aureus and c) C.albicans.

Figure 12. Plausible mechanism of Antimicrobial activity of ZnONPs. 
Figures

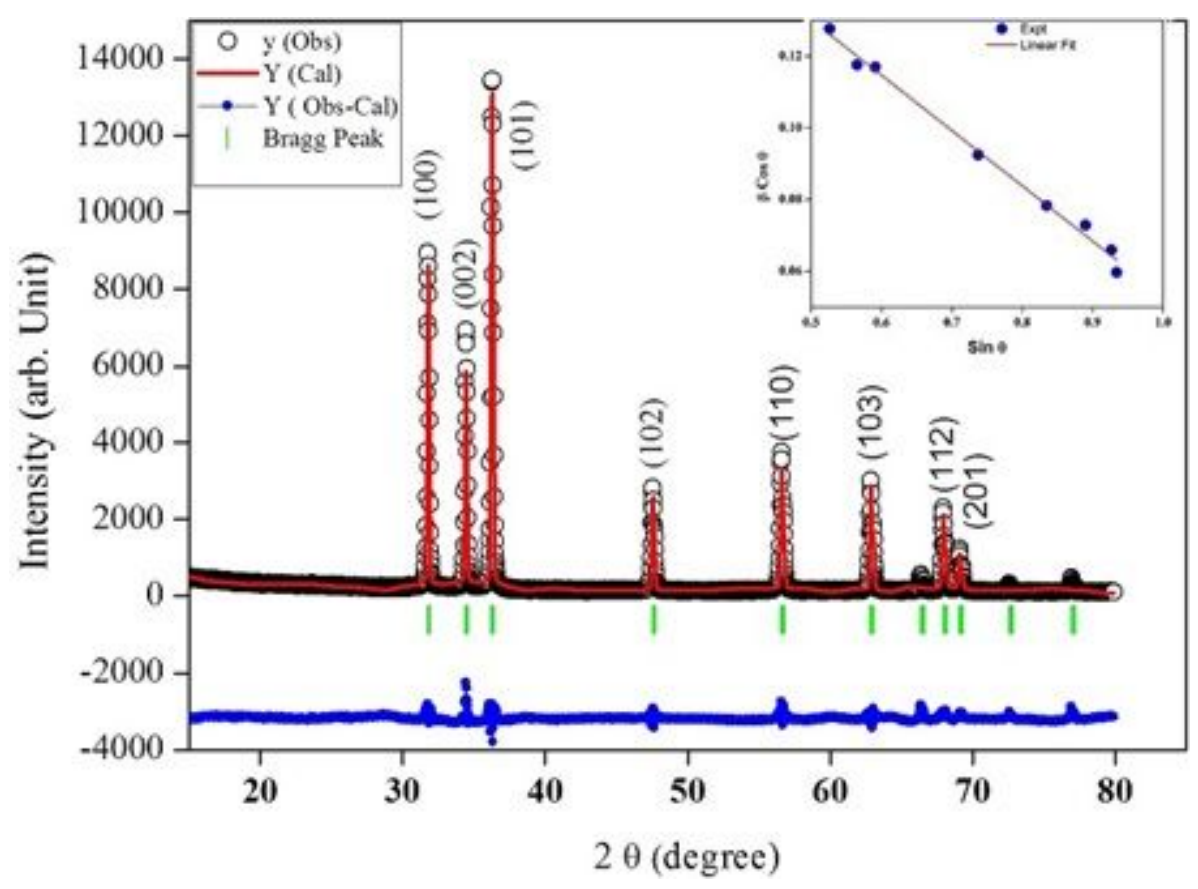

Figure 1

Rietveld refinement of XRD pattern and Inset:Williamson-Hall plot for ZnONPs.

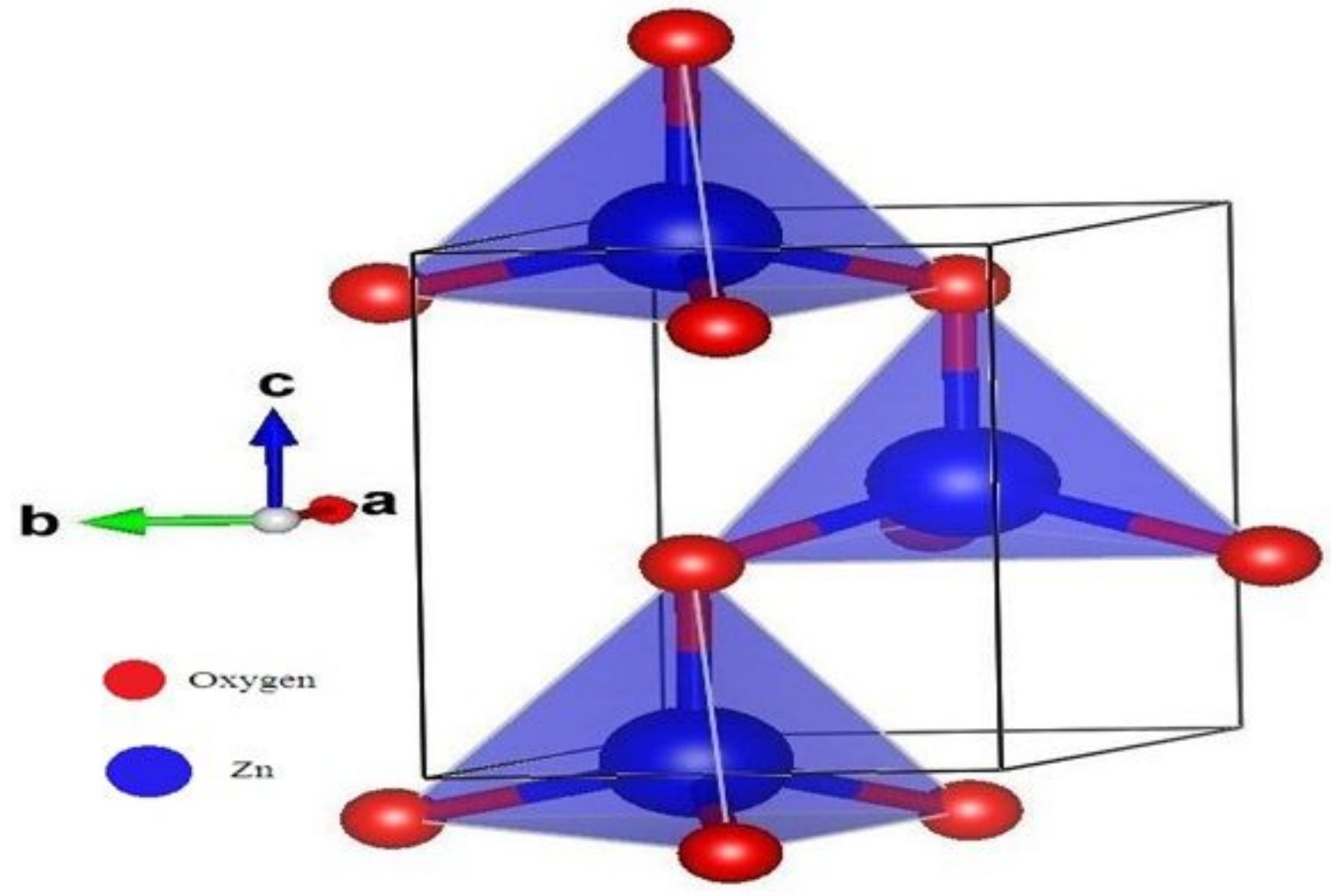

Figure 2 
Hexagonal Closed Packed Wurtzite crystal structure of ZnONPs with space group P 63 m c.

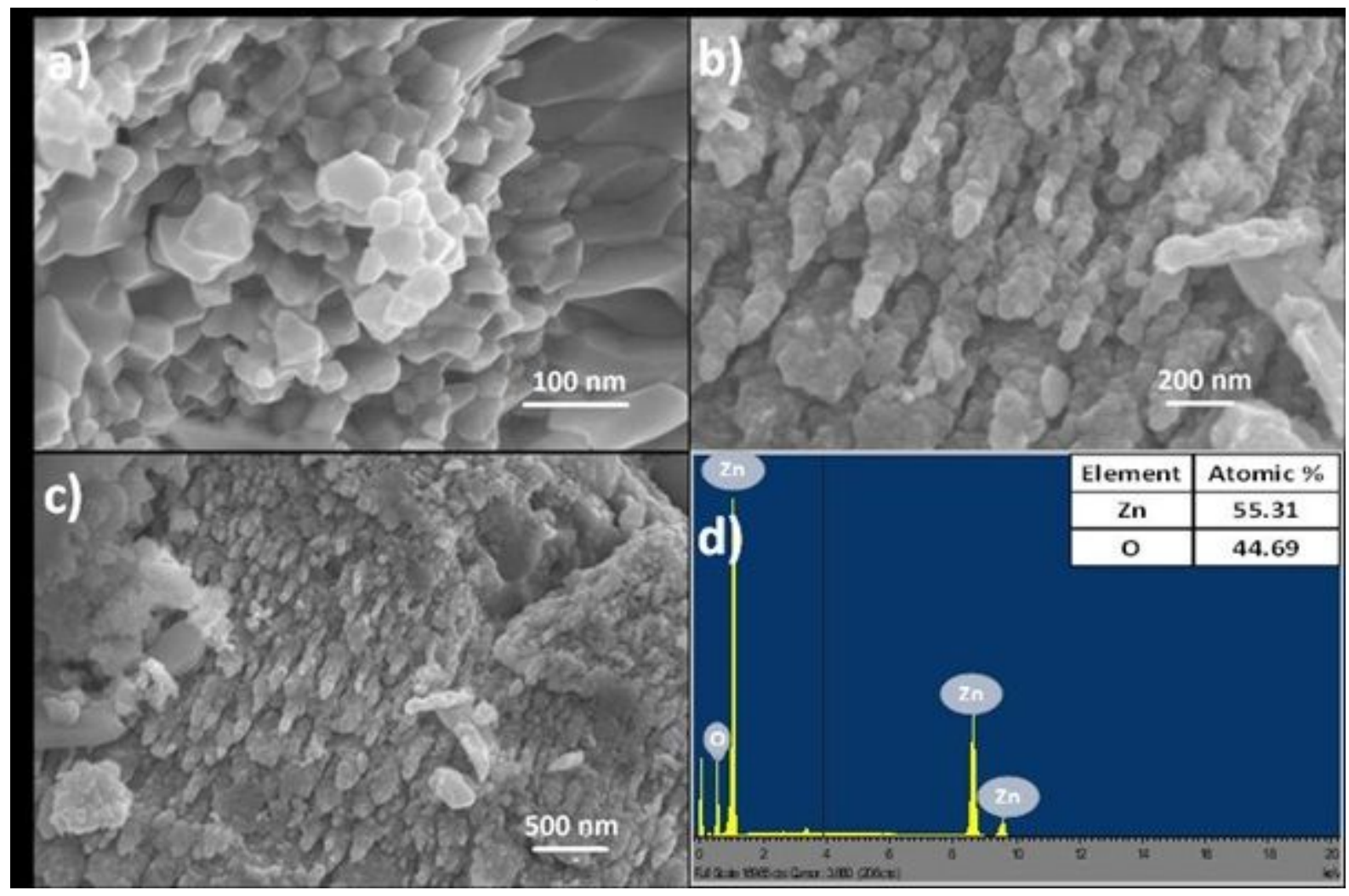

Figure 3

SEM images and EDS spectra of as-synthesized ZnO nanostructures at different magnifications.

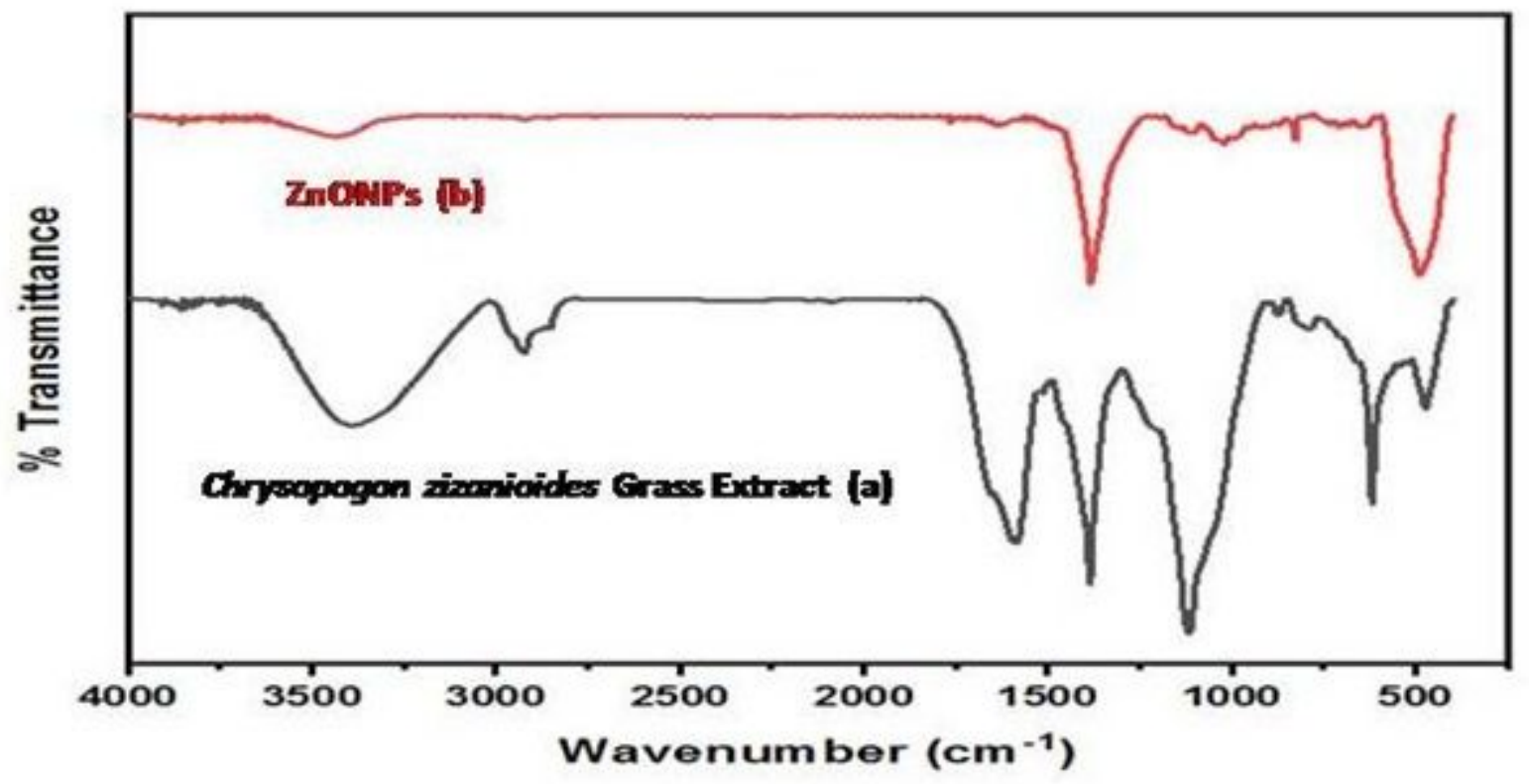

Figure 4

a) FTIR spectra of Chrysopogonzizanioidesgrass extract and b) ZnONPsin the range of $400-4000 \mathrm{~cm}-1$. 

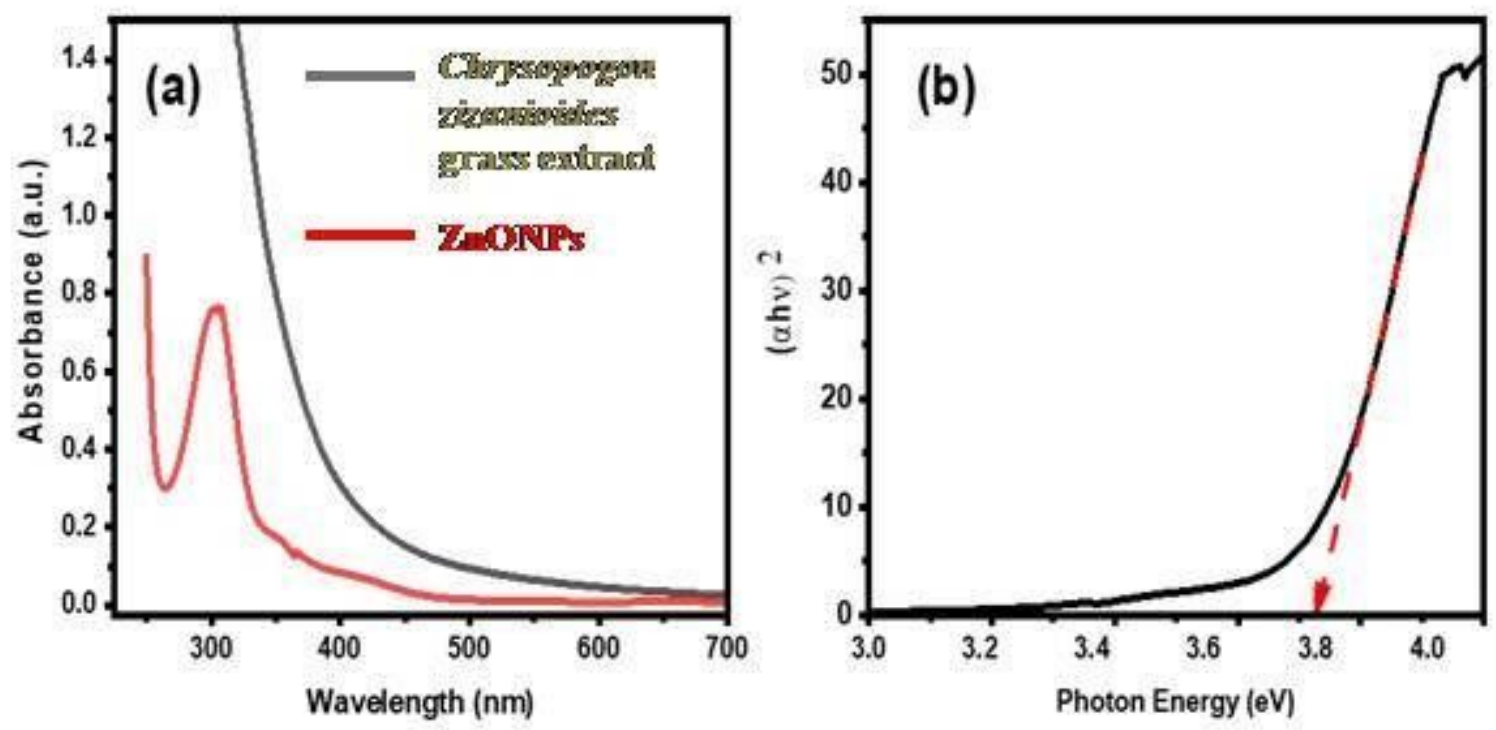

Figure 5

a) UV-Visible absorption spectrum of Chrysopogonzizanioidesgrassextractand ZnONPs b) Optical band gap of synthesized ZnONPs.
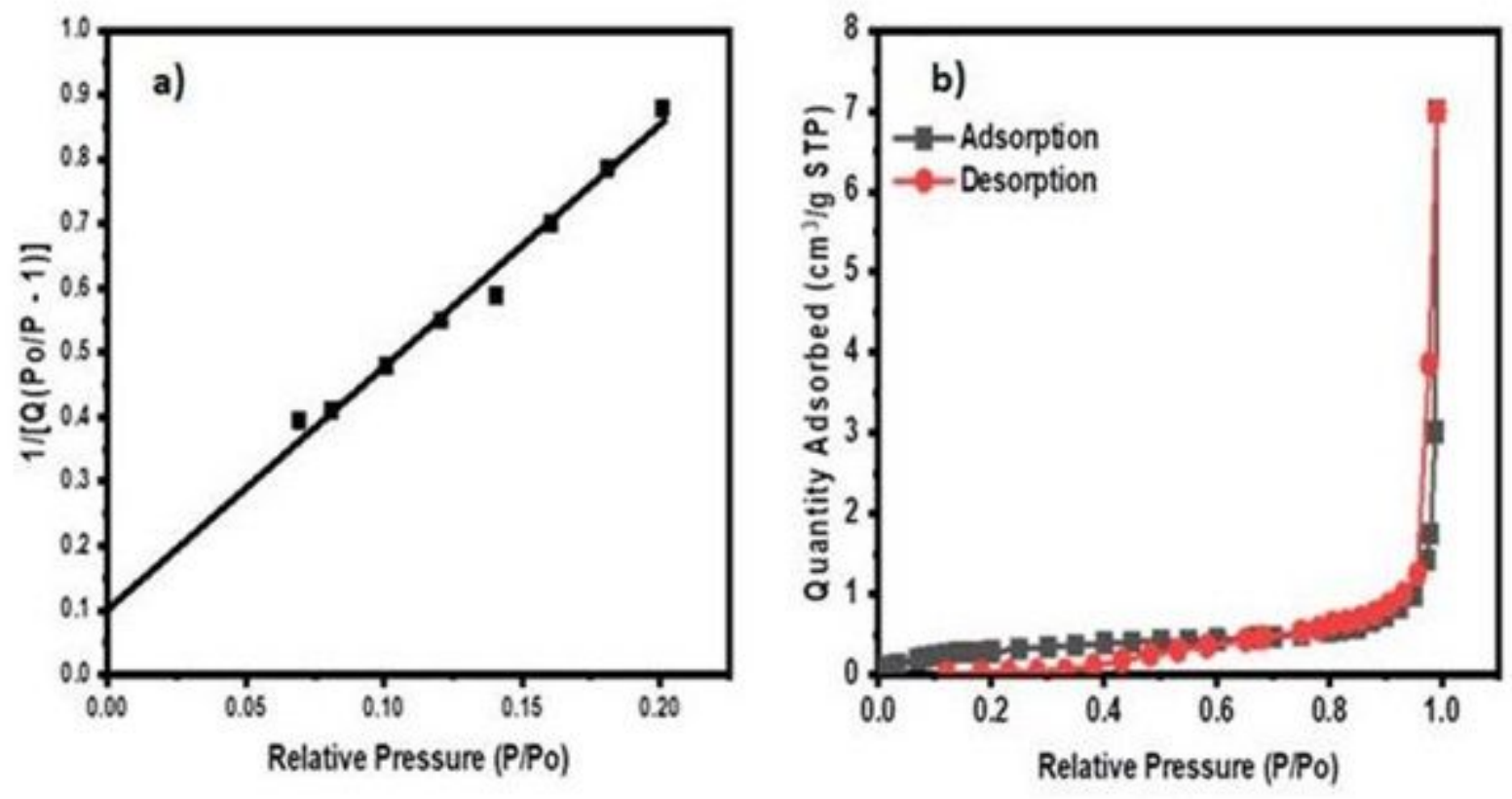

Figure 6

a) The fitting curve of the BET surface area and b) Nitrogen adsorptionisotherm of ZnONPs. 

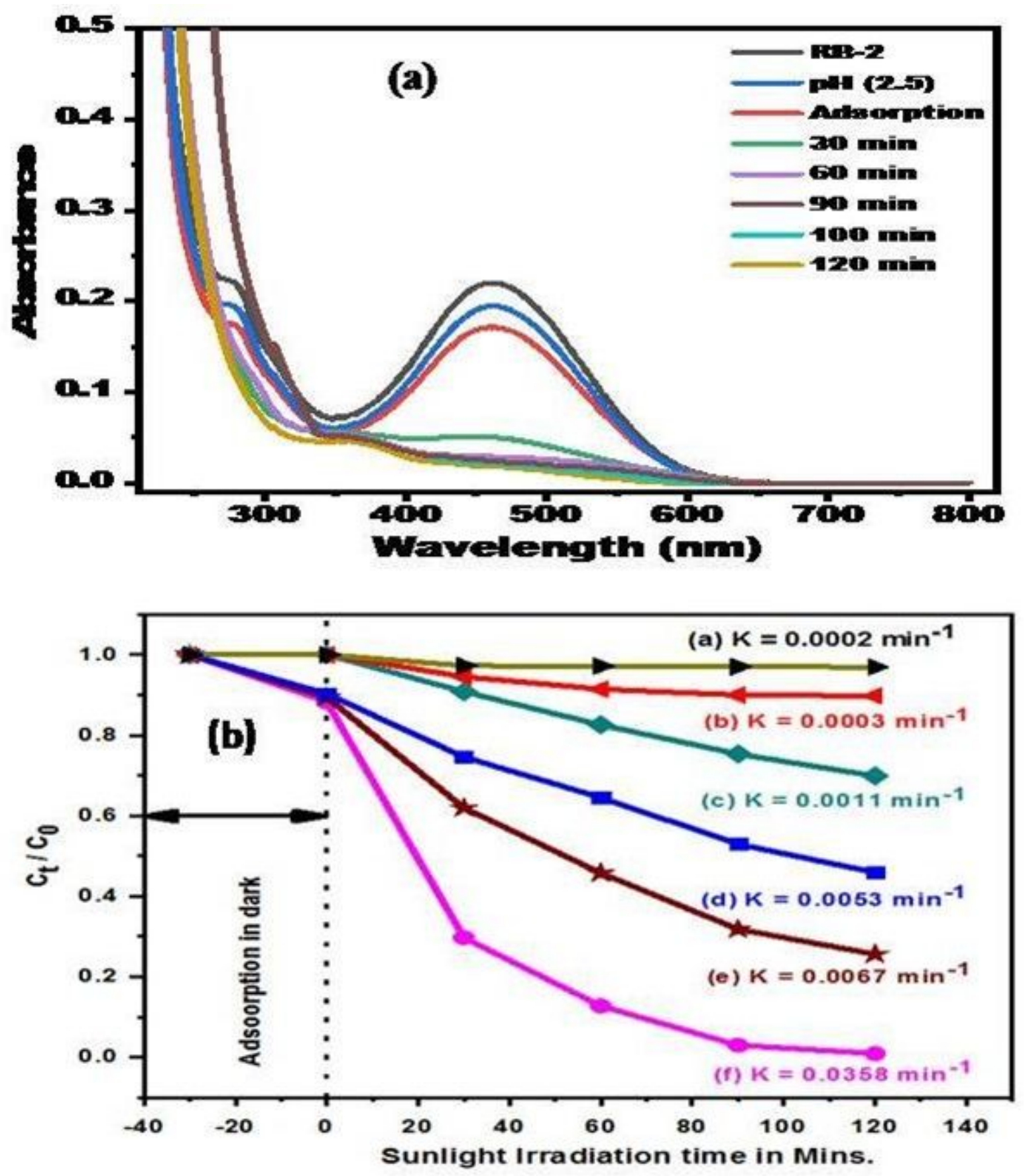

Figure 7

a) Spectral Change during the degradation of RB2 dye in the presence of ZnONPs. b) A Plot of the change absorbance Vs Irradiation time in the presence of ZnONPs Catalyst. 


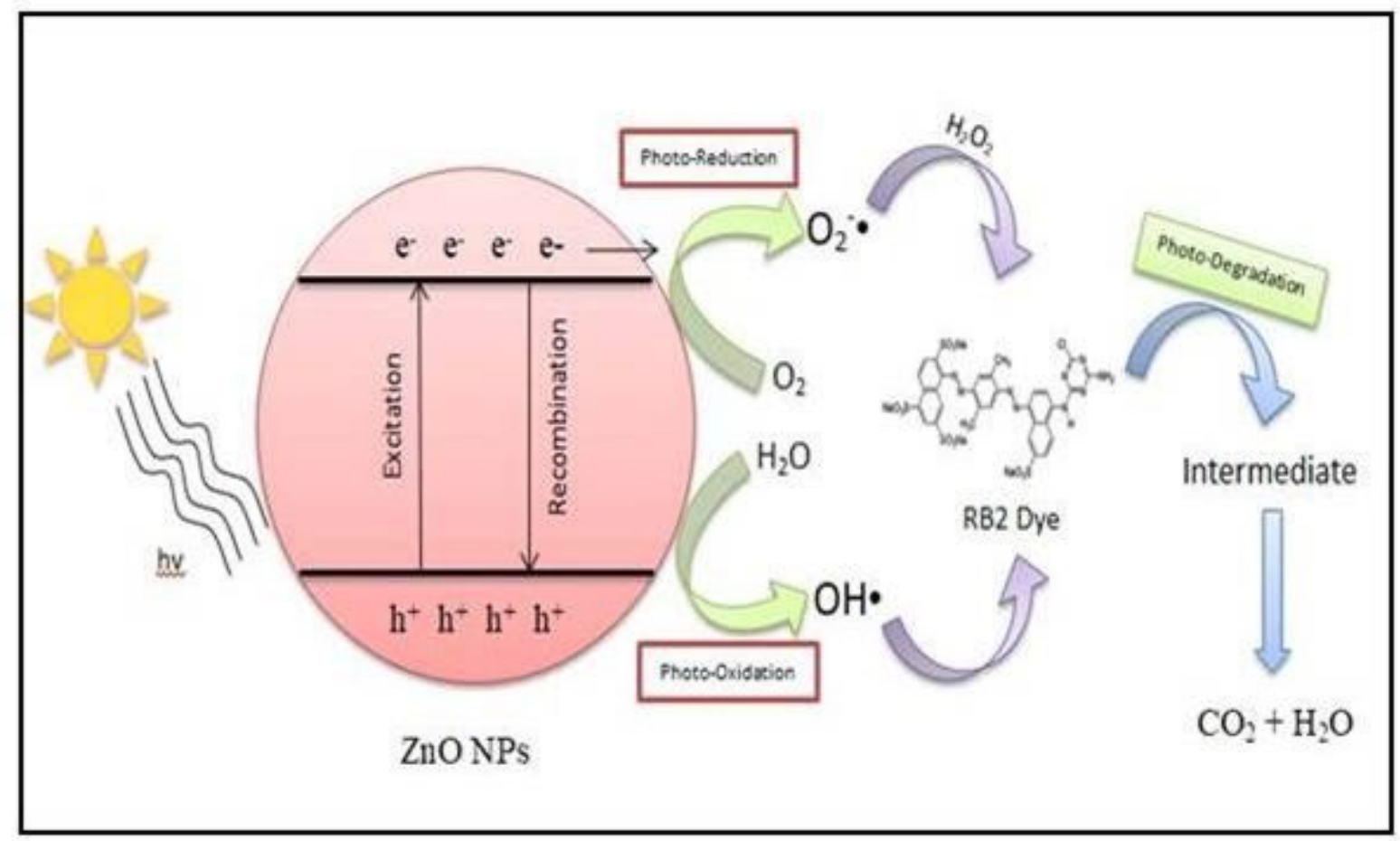

Figure 8

Possible Mechanism for the photocatalytic RB2 dye degradation under sunlight irridation using ZnONPs.
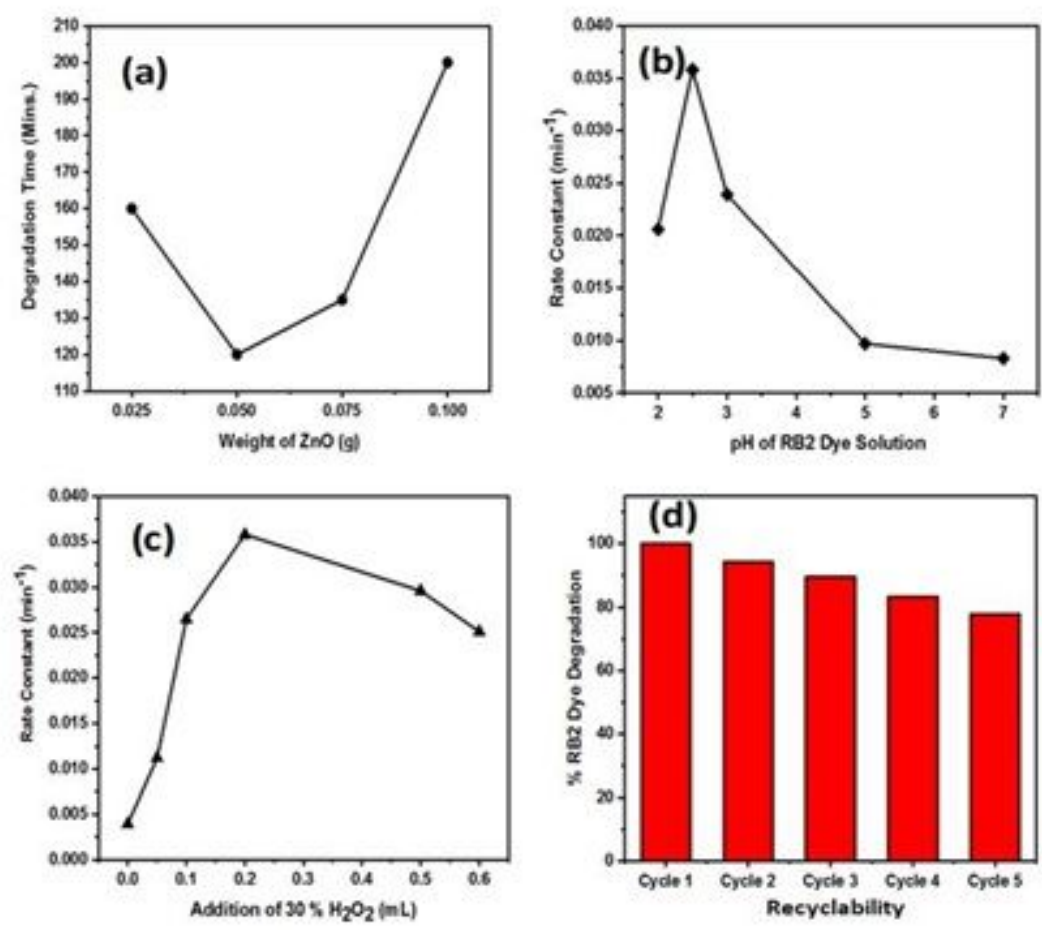

Figure 9

Effects of a) Catalyst b) pH variation c) H2O2 Variation d) Recyclability of ZnONPs. 


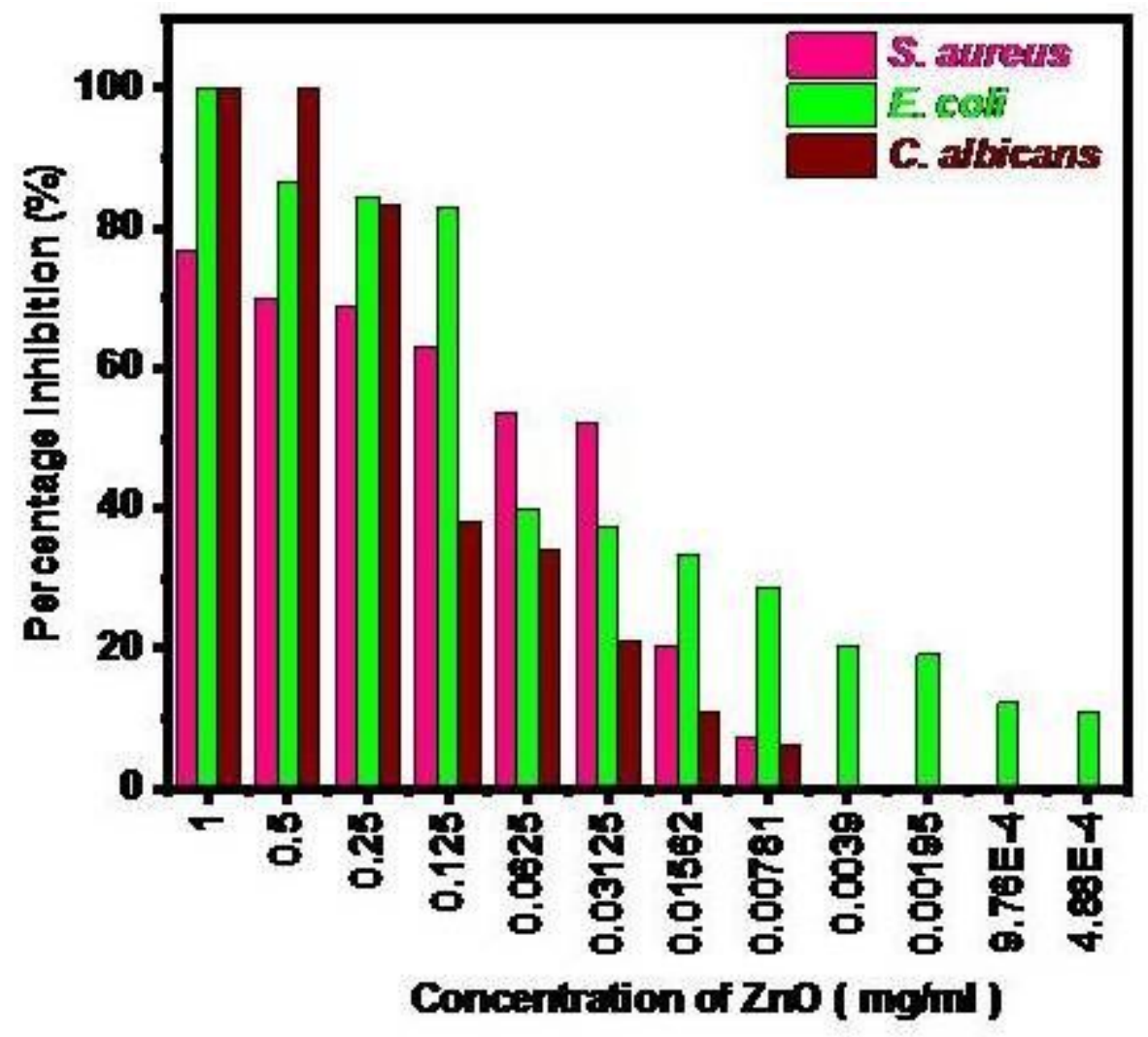

Figure 10

Percentage inhibition of microbes by different concentration of $\mathrm{ZnO}$ on S. Aureus, E. Coli and C.albicans. 


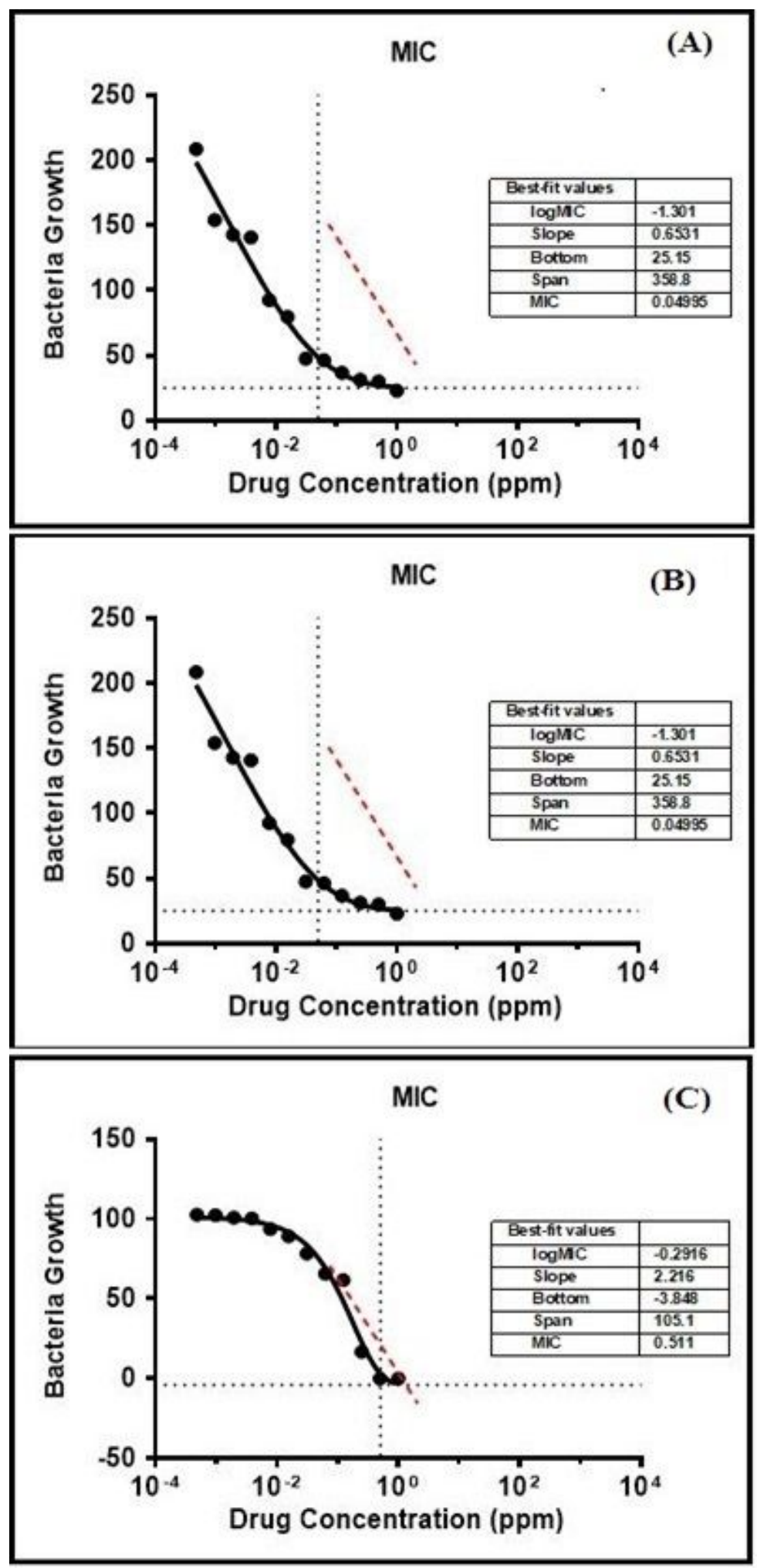

Figure 11

Minimum inhibitory concentration (MIC) for a) E. coli b) S. aureus and c) C.albicans. 


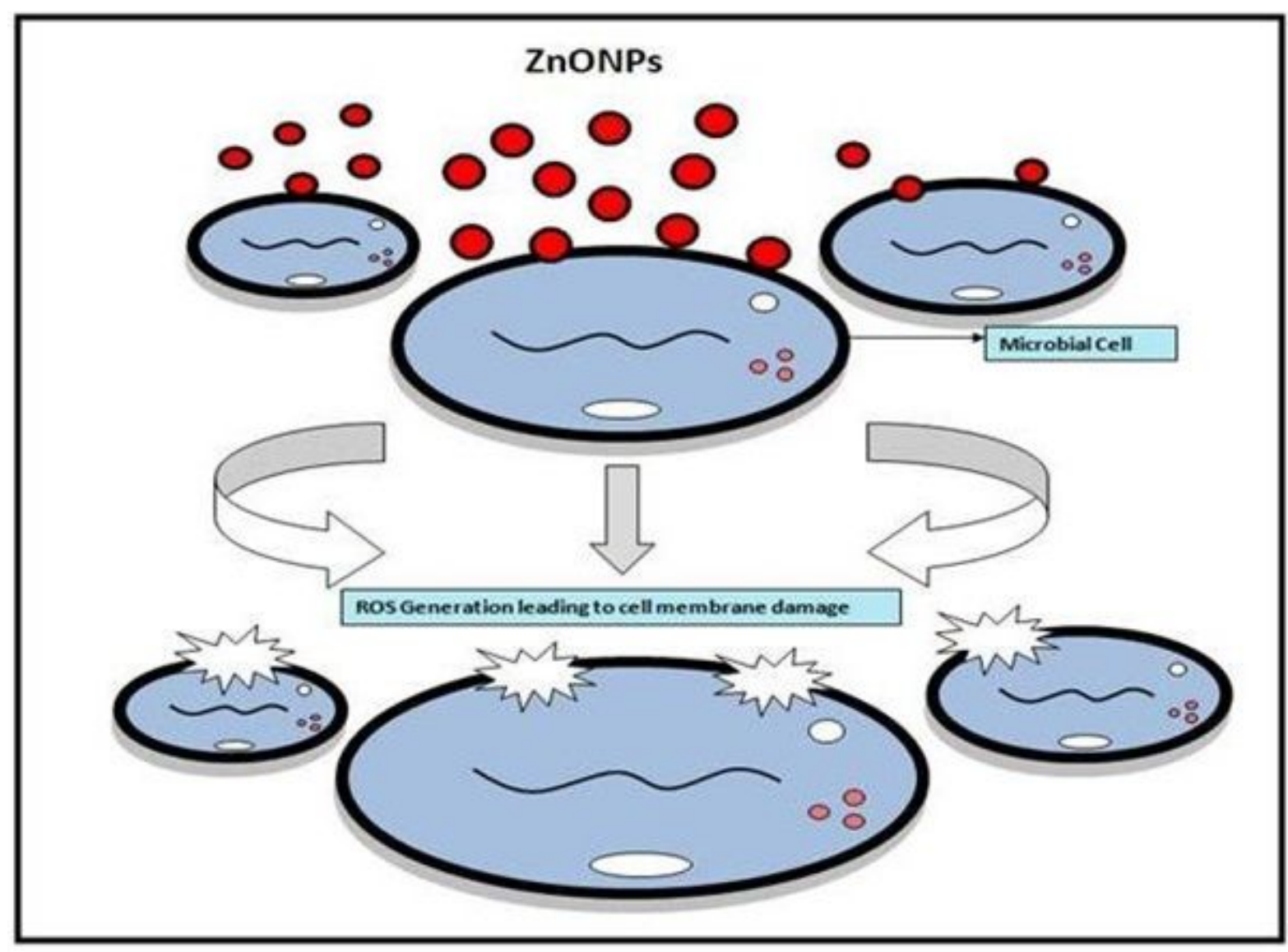

Figure 12

Plausible mechanism of Antimicrobial activity of ZnONPs. 